\title{
General Announcements
}

\section{Grants-In-Aid from the JCPDS-International Centre for Diffraction Data}

Each year the JCPDS-International Centre for Diffraction Data extends financial support in the form of Grants-in-Aid to a limited number of scientists for the provision of X-ray powder data. These grants are intended to supplement existing funded projects involving the preparation and recording of data from new materials. First time grants are usually of the order of $\$ 2,000$ to $\$ 5,000$ for projects resulting in 10-25 new patterns. Proposals addressing the immediate needs of the powder diffraction community will be given highest priority, especially projects involving organic compounds and materials used in forensic investigations. Materials involved with any new and evolving technologies are also of specific interest.

Grants-in-Aid proposals will be considered from any qualified investigator who can demonstrate expertise in the preparation of high quality powder diffraction patterns, or in the synthesis of high purity materials, provided that such materials are of interest to the Grants-in-Aid Committee. All Grant-in-Aid recipients are required to prepare biannual reports on progress and extension of a Grant beyond a given year is contingent on satisfactory performance. Proposals should be submitted in accordance with specified guidelines and new proposals are reviewed in January of each year. A final decision is generally reached in March. All Grants become effective the beginning of the JCPDS fiscal year, currently 1st April.

Guidelines for the preparation of Grant proposals can be obtained from the JCPDS and proposals for grants should be addressed to:

Secretary, JCPDS-International Centre for Diffraction Data

1601 Park Lane

Swarthmore, PA 19081, U.S.A.

Correction: In Volume 2, Number 2, page 126, the photograph of Camden R. Hubbard appeared over the name of Wilson DeCamp II - whose photograph should have been used. The editors of Powder Diffraction regret this error. 